\title{
PENGARUH FREKUENSI PULSE PENGELASAN GTAW PADA ALUMINIUM ALLOY 6061
}

\author{
Ari Wibowo*, Nugroho Pratomo Aryanto, Cahyo Budi Nugroho dan Muhammad Ismail \\ Teknik Mesin, Politeknik Negeri Batam, Jl. Ahmad Yani, Batam Center, Batam 29461 Kepulauan \\ Riau, Indonesia \\ *E-mail: ariwibowo@polibatam.ac.id
}

\begin{abstract}
Abstrak
AA6061 banyak digunakan untuk industri luar angkasa, kendaraan bermotor dan industri kelautan terutama untuk kapal cepat. Pengelasan paduan aluminium dengan GTAW sering menghasilkan cacat las seperti porosity dan hot cracking. Paper ini menggambarkan pengaruh pulse frequency terhadap sifat microhardness, porosity dan makrostructure pada pengelasan GTAW. Penelitian ini menggunakan aluminium 6061 sebagai base metal dan tanpa menggunakan filler metal. Pulse frequency divariasikan dari $0 \mathrm{~Hz}$ sampai $10 \mathrm{~Hz}$. Hasil makrostruktur menunjukkan bahwa kedalaman penetrasi maksimum terjadi pada pulse frequency $6 \mathrm{~Hz}$, sedangkan lebar penetrasi lasan maksimum terjadi saat tidak menggunakan pulse frequency. Pengujian kekerasan mikro menunjukkan bahwa terjadinya kekerasan maksimum pada pulse frequency $6 \mathrm{~Hz}$ sedangkan kekerasan paling rendah terjadi pada pulse frequency $10 \mathrm{~Hz}$. Pengelasan AA 6061 tanpa filler ini menghasilkan porositas yang bisa berdampak pada kekerasan pada weld metal.
\end{abstract}

Kata kunci: pulse frequency, AA6061, GTAW, porositas, struktur makro, microhardness,

\begin{abstract}
AA6061 is widely used for the space industry, motor vehicles and marine industry, especially for spead boats. aluminium alloys Welding with GTAW often produces weld defects such as porosity and hot cracking. This paper describes the effect of pulse frequency on the properties of microhardness, porosity and macrostructure in GTAW welding. This study used alluminum 6061 as a base metal and without filler metal. Pulse frequency is varied from $0 \mathrm{~Hz}$ to $10 \mathrm{~Hz}$. The macrostructure results showed the maximum penetration depth occured at pulse frequency $6 \mathrm{~Hz}$, while the maximum penetration width occured when did not pulse frequency. Micro hardness testing showed that the maximum hardness occured at pulse frequency $6 \mathrm{~Hz}$ while the lowest hardness occured at pulse frequency $10 \mathrm{~Hz}$. AA 6061 welding without metal filler produced porosity which can have an impact on the hardness of the weld metal.
\end{abstract}

Keywords: pulse frequency, AA6061, GTAW, porosity, macrostructure, microhardness,

\section{PENDAhuluan}

Paduan aluminium AA6061 banyak digunakan untuk industri luar angkasa, kendaraan bermotor dan industri kelautan terutama untuk kapal cepat [3]. Aluminium jenis ini memiliki kandungan magnesium dan silicon dalam jumlah besar yang mana akan mengalami peningkatan kekuatan dengan cara precipitation hardening [6]. Aluminium merupakan logam yang memiliki lapisan oksida yang terdapat pada permukaannya. GTAW bisa digunakan untuk mengelas material yang memiliki lapisan oksida pada permukaannnya seperti aluminium. GTAW juga biasanya digunakan untuk mengelas part-part kecil yang sulit dilas dengan SMAW. Dalam mengelas aluminium dengan
GTAW diperlukan arus AC. Arus AC digunakan untuk membuang lapisan oksida yang terdapat pada permukaan. Pengelasan paduan aluminium dengan GTAW sering menghasilkan cacat las seperti porosity, hot cracking dan incomplete fusion [4]. Struktur mikro dan sifat mekanik aluminium akan berubah ketika dilas.

Pada proses pengelasan pulse GTAW, variable input sangat mempengaruhi sifat mekanik hasil pengelasan [5] contohnya pulse current dan pulse frequency. Dengan sedikit merubah variable tersebut bisa dihasilkan sifat mekanik yang sangat berbeda. Penelitian ini menggunakan variable pulse frequency yang bisaa terdapat pada GTAW untuk mengetahui pengaruhnya terhadap hasil penetrasi dan kekerasan pada aluminium 6061. Peak current 
pada pulse digunakan untuk menghasilkan penetrasi yang maksimal pada pengelasan sedangkan background current digunakan untuk menghasilkan busur api yang stabil [2].

\section{METODE PENELITIAN}

Plate AA6061 dengan komposisi kimia seperti tabel 1 dilas pada pemukaannya menggunakan GTAW. Plate disiapkan dengan ketebalan $12 \mathrm{~mm}$ dipotong dengan bandsaw menjadi ukuran $150 \mathrm{~mm}$ x $100 \mathrm{~mm}$. Plate tersebut kemudian dilas dengan GTAW dengan parameter seperti Tabel 2.

Tabel 1. Komposisi kimia (wt\%) standard AA6061 [1]

\begin{tabular}{lclc}
\hline Unsur & \%wt & Unsur & \%wt \\
\hline $\mathrm{Si}$ & $0,4-0,8$ & $\mathrm{Zn}$ & $<0,25$ \\
$\mathrm{Mg}$ & $0,8-1,2$ & $\mathrm{Ti}$ & $<0,15$ \\
$\mathrm{Cu}$ & $0,15-0,4$ & $\mathrm{Cr}$ & $0,04-0,35$ \\
$\mathrm{Mn}$ & $<0,15$ & $\mathrm{Al}$ & Bal \\
$\mathrm{Fe}$ & $<0,7$ & & \\
\hline
\end{tabular}

Tabel 2. parameter pengelasan

\begin{tabular}{ll}
\hline Pulse frequency & $: 0,2,4,6,8,10 \mathrm{~Hz}$ \\
Ac pulse & $: 150 \mathrm{~Hz}$ \\
Peak current & $: 180 \mathrm{~A}$ \\
Background current & $: 80 \mathrm{~A}$ \\
AC balance & $: 70 \%(-)$ \\
Pulse ontime & $: 50 \%$ \\
Shielding gas & $:$ Argon \\
Gas flowrate & $: 20 \mathrm{~L} /$ minute \\
Electrode & $: 2 \%$ thoriated \\
Electrode size & $: 3,2 \mathrm{~mm}$ \\
Arc length & $: 2 \mathrm{~mm}$ \\
Travel speed & $: 3 \mathrm{~cm} /$ minute \\
\hline
\end{tabular}

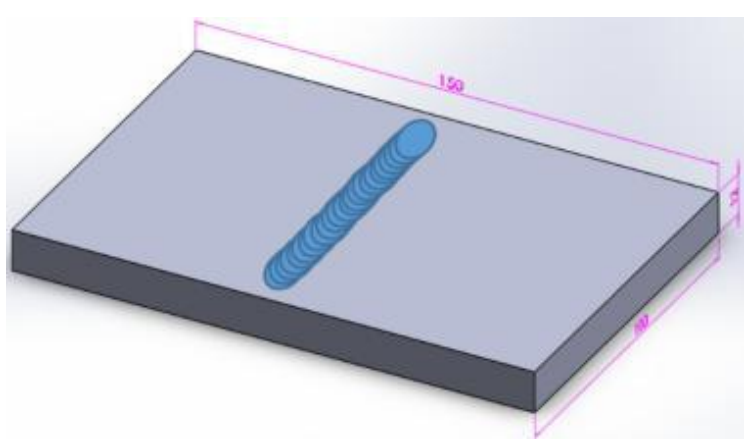

Gambar 1. Desain pengelasan

Pengelasan dikerjakan sesuai desain pada Gambar 1. Pengelasan dilakukan dengan memadukan mesin GTAW manual dengan plasma cutting carrier sehingga berjalan dengan kecepatan konstan, ditunjukkan oleh Gambar 2.

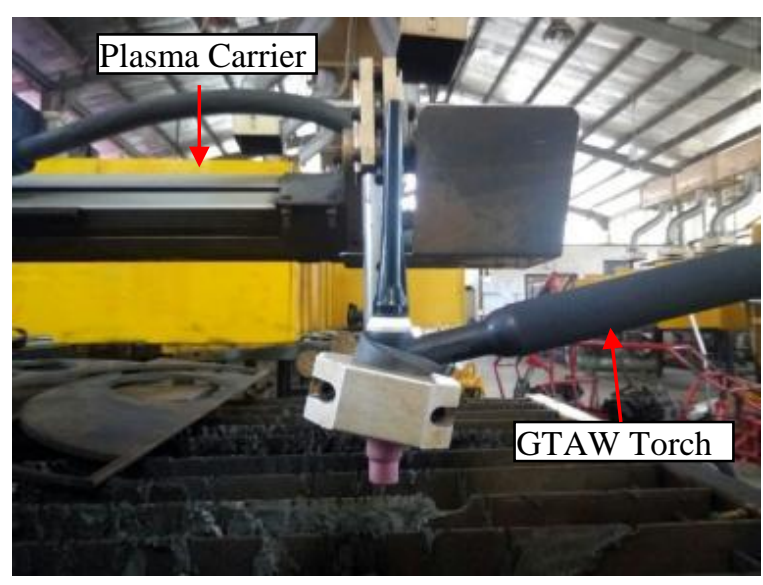

Gambar 2. Mesin GTAW modifikasi

Pengambilan data struktur makro dilakukan pada jarak 3,5 $\mathrm{mm}$ dari bead lasan awal. Material disiapkan dengan menghaluskan permukaan uji makro menggunakan mesin grinding sampai pada grit 1500. Kemudian material dietsa menggunakan larutan $\mathrm{NaOH}\left(10 \mathrm{ml} \mathrm{NaOH}+90 \mathrm{ml} \mathrm{H}_{2} \mathrm{O}\right)$ selama 5 menit dilanjutkan dengan larutan $\mathrm{HNO}_{3}(25 \mathrm{ml}$ $\mathrm{HNO}_{3}+75 \mathrm{ml} \mathrm{H}$ O) selama 3 menit.

Pengujian kekerasan mikro Vickers dilakukan dengan beban $1 \mathrm{~kg}$ dan dwelling time 25s dengan skema seperti Gambar 3. Pengujian kekerasan dimulai pada bagian atas dengan jarak $0,5 \mathrm{~mm}$ dari tepi material. Pengujian kekerasan dilanjutkan sebanyak 15 kali sampai mengenai base metal dengan jarak masing-masing pengujian sebesar 0,5 $\mathrm{mm}$.

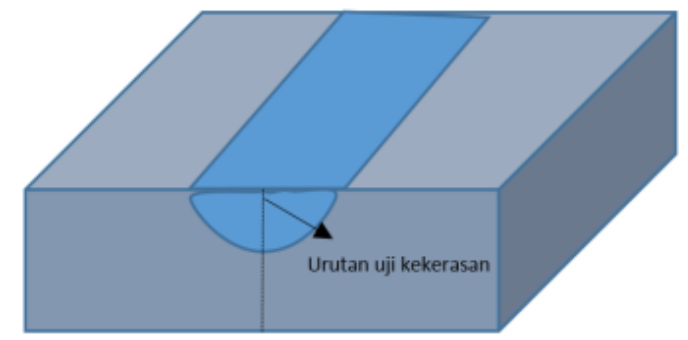

Gambar 3. Desain pengujian kekerasan vicker

Pengujian phase arry ultrasonic (PAUT) dilakukan untuk mengetahui porosity yang terbentuk akibat pengelasan. Pengujian dilakukan dengan mengambil tiga sampel penelitian yaitu pada frekuensi pulse $6 \mathrm{~Hz}$.

\section{HASIL DAN PEMBAHASAN}

Berikut adalah hasil uji OES (Tabel 3) untuk memastikan komposisi AA 6061 sesuai standard industri. Dari hasil pengujian didapatkan bahwa komposisi kimia unsur paduan AA 6061 yang digunakan sesuai dengan standard.

Tabel 3. komposisi kimia (wt\%) AA6061 


\begin{tabular}{lclc}
\hline Unsur & \%wt & Unsur & \%wt \\
\hline $\mathrm{Si}$ & 0,756 & $\mathrm{Zn}$ & 0,064 \\
$\mathrm{Mg}$ & 0,949 & $\mathrm{Ti}$ & 0,023 \\
$\mathrm{Cu}$ & 0,247 & $\mathrm{Cr}$ & 0,079 \\
$\mathrm{Mn}$ & 0,089 & $\mathrm{Al}$ & $\mathrm{Bal}$ \\
$\mathrm{Fe}$ & 0,273 & & \\
\hline
\end{tabular}

Hasil pengamatan struktur makro dan pengukuran penetrasi pengelasan menunjukkan bahwa semakin pulse frequency dari $0 \mathrm{~Hz}$ sampai 10 $\mathrm{Hz}$ sudah sangat mempengaruhi penetrasi lasan seperti yang ditunjukkan oleh gambar 4 dan tabel 3 . Penetrasi paling dalam didapatkan ketika pulse frequency $6 \mathrm{~Hz}$. Pulse frequency di atas $6 \mathrm{~Hz}$ akan menyebabkan penetrasi semakin dangkal. Semakin tinggi pulse frequency akan menyebabkan lebar penetrasi semakin kecil. weld metal paling lebar didapatkan ketika pulse frequency $0 \mathrm{~Hz}$. Hal ini diakibatkan oleh semakin tinggi pulse frequency maka akan menyebabkan heat input semakin turun [9].

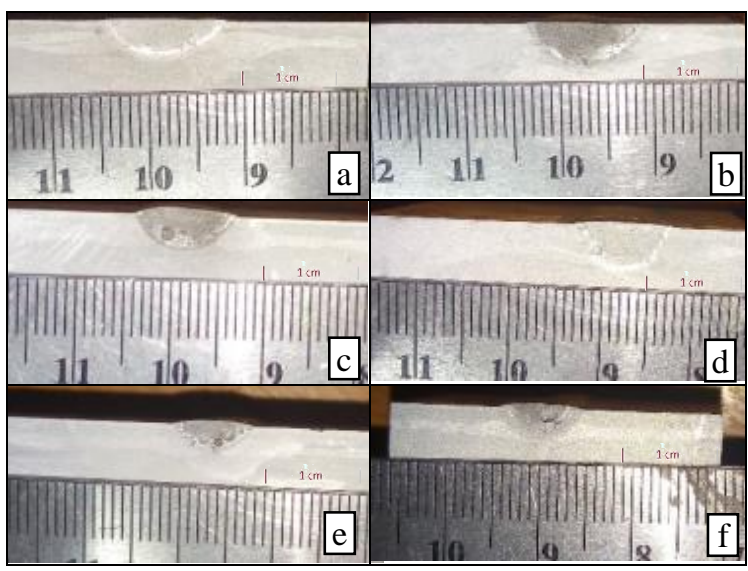

Gambar 4. Struktur makro pengelasan a) $0 \mathrm{~Hz}$, b) $2 \mathrm{~Hz}$, c) $4 \mathrm{~Hz}$, d) $6 \mathrm{~Hz}$, e) $8 \mathrm{~Hz}$, f) $10 \mathrm{~Hz}$

Tabel 4. Hasil pengukuran penetrasi pengelasan Pulse Deepth $(\mathrm{mm}) \quad$ Width $(\mathrm{mm})$ frequency (Hz)

\begin{tabular}{ccc}
\hline$(\mathbf{H z})$ & & \\
\hline 0 & 3,6 & 11,4 \\
2 & 4,12 & 11,36 \\
4 & 4,12 & 9,88 \\
6 & 5,08 & 9,44 \\
8 & 3,22 & 8,24 \\
10 & 3,08 & 7,78 \\
\hline
\end{tabular}

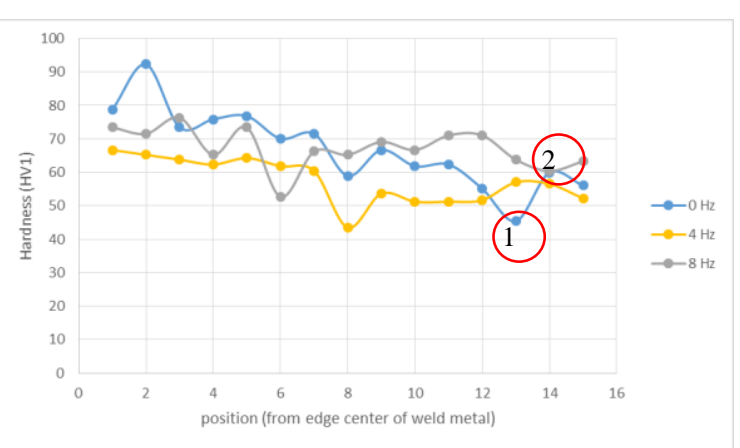

Gambar 5. Uji kekerasan Vickers pada pulse frequency $0,4,8 \mathrm{~Hz}$

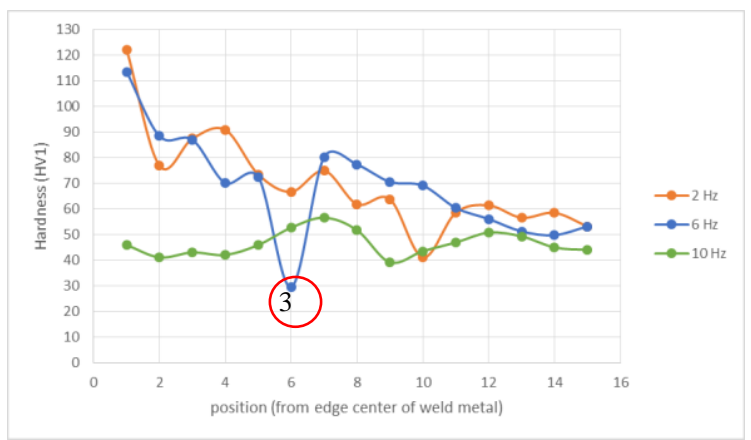

Gambar 6. Uji kekerasan Vickers pada pulse frequency $2,6,10 \mathrm{~Hz}$

Tabel 5. Identifikasi jenis struktur makro pada berbagai pulse frequency

\begin{tabular}{|c|c|c|c|c|c|c|c|}
\hline \multirow{4}{*}{$\begin{array}{l}\text { Pos } \\
\text { itio } \\
\text { n }\end{array}$} & \multirow{4}{*}{$\begin{array}{l}\text { Jarak } \\
\text { ke tepi } \\
(\mathrm{mm})\end{array}$} & \multicolumn{6}{|c|}{ Pulse Frequency } \\
\hline & & $\mathbf{0}$ & \begin{tabular}{l|l}
2 \\
\end{tabular} & 4 & 6 & 8 & 10 \\
\hline & & Hz & $\mathbf{H z}$ & $\mathbf{H z}$ & H & $\mathbf{H}$ & $\mathbf{H}$ \\
\hline & & & & & $\mathbf{z}$ & $\mathbf{z}$ & $\mathbf{z}$ \\
\hline 1 & 0.5 & \multirow{7}{*}{$\begin{array}{l}\sum_{0}^{\frac{\pi}{0}} \\
\frac{0}{0} \\
\sum^{0}\end{array}$} & \multirow{8}{*}{$\frac{\pi}{\frac{\pi}{0}}$} & \multirow{8}{*}{$\begin{array}{l}\frac{\pi}{0} \\
\sum^{0} \\
0 \\
0 \\
3\end{array}$} & \multirow{10}{*}{$\begin{array}{l}\frac{\pi}{0} \\
\sum_{0}^{0} \\
\frac{0}{0} \\
3\end{array}$} & \multirow{6}{*}{$\begin{array}{l}\frac{\pi}{0} \\
\frac{0}{0} \\
\frac{0}{2}\end{array}$} & \multirow{6}{*}{$\begin{array}{l}\frac{\pi}{0} \\
\sum^{0} \\
\frac{0}{0} \\
3\end{array}$} \\
\hline 2 & 1 & & & & & & \\
\hline 3 & 1.5 & & & & & & \\
\hline 4 & 2 & & & & & & \\
\hline 5 & 2.5 & & & & & & \\
\hline 6 & 3 & & & & & & \\
\hline 7 & 3.5 & & & & & \multirow{9}{*}{ 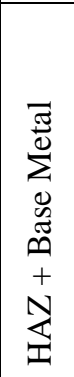 } & \multirow{9}{*}{ 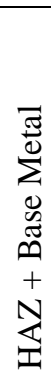 } \\
\hline 8 & 4 & \multirow{8}{*}{ 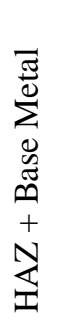 } & & & & & \\
\hline 9 & 4.5 & & \multirow{3}{*}{$\begin{array}{l}0 \\
\tilde{\Xi} \\
\tilde{\Xi}\end{array}$} & \multirow{3}{*}{$\begin{array}{l}0 \\
\text { 心 } \\
\tilde{\Xi}\end{array}$} & & & \\
\hline 10 & 5 & & & & & & \\
\hline 11 & 5.5 & & & & \multirow{5}{*}{$\begin{array}{l}\sum_{m} \\
+ \\
\pm \\
\mathbb{I}\end{array}$} & & \\
\hline 12 & 6 & & \multirow{4}{*}{$\underset{2}{3}$} & \multirow{4}{*}{ 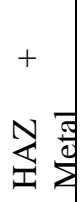 } & & & \\
\hline 13 & 6.5 & & & & & & \\
\hline 14 & 7 & & & & & & \\
\hline 15 & 7.5 & & & & & & \\
\hline
\end{tabular}

Pada Gambar 5 dan 6 ditunjukkan bahwa terjadi penurunan kekerasan Vickers ketika pulse frequency meningkat pada weld metal, sedangkan untuk haz dan base metal tidak terlalu signifikan. Bisa dilihat pada Tabel 5 bagian weld metal dan base metal. Pada Gambar 5 dan 6 terdapat tanda lingkaran yang menunjukkan terjadinya penurunan kekerasan yang sangat besar. Hal ini diakibatkan oleh kemungkinan 
terbentuknya porositas yang berada pada sub surface seperti ditunjukkan oleh Gambar 7 pada bagian 3 dimana hasil indentasi tidak berupa piramida sempurna namun seperti ada cekungan. Kekerasan paling rendah didapatkan ketika material dilas dengan pulse frequency sebesar $10 \mathrm{~Hz}$, dimana tidak ada perbedaan kekerasan Antara weld metal dengan HAZ maupun base metal. Secara umum kekerasan pada weld metal lebih besar dibandingkan dengan Haz dan base metal hal ini bisa diakibatkan oleh terjadinya precipitate hardening ketika AA 6061 berada pada suhu di atas $400^{\circ} \mathrm{C}$ [7]. Selain karena precipate hardening, peningkatan kekerasan pada weld metal juga disebabkan karena penghalusan butir struktur mikro yang diakibatkan oleh thermal cycle [8].

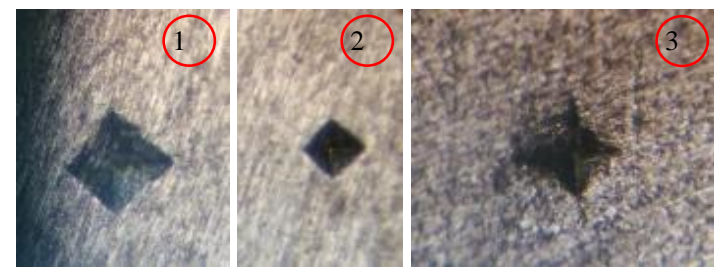

Gambar 7. Bentuk indentasi pada posisi 1) 13 $(0 \mathrm{~Hz}), 2) 14(0 \mathrm{~Hz}), 3) 6(6 \mathrm{~Hz})$

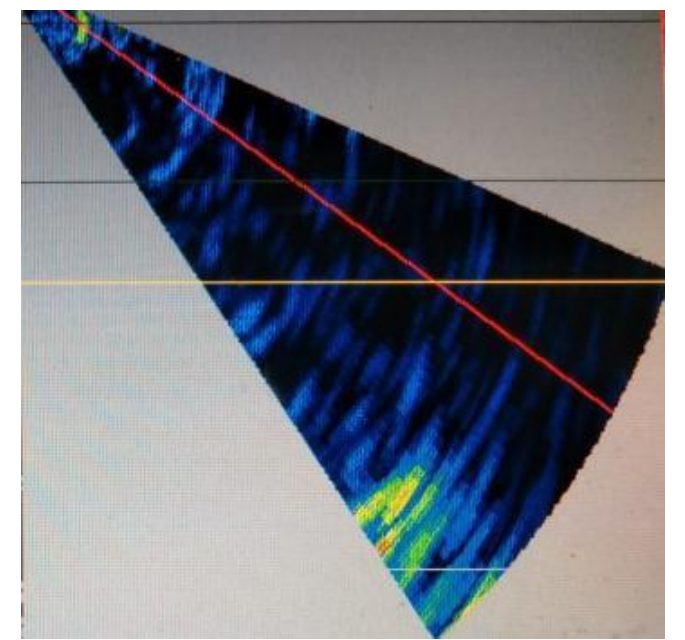

Gambar 8. Pengujian phase array UT pada pulse frequency $6 \mathrm{~Hz}$

Untuk membuktikan terbentuknya porositas pada hasil pengelasan dilakukan pengujian phase array UT seperti ditunjukkan pada Gambar 8 . Terdapat porositas yang berada sekitar $3 \mathrm{~mm}$ di bawah permukaan lasan.

\section{KESIMPULAN}

Meningkatnya pulse frequency menyebabkan lebar lasan semakin besar, sedangkan kedalaman lasan didapakan ketika pulse frequency $6 \mathrm{~Hz}$, hal ini berkaitan dengan heat input yang dihasilkan karena perbedaan pulse frequency. Kekerasan weld metal tertinggi didapatkan ketika pulse frequency $6 \mathrm{~Hz}$. Kekerasan terendah didapatkan ketika pulse frequency $10 \mathrm{~Hz}$. Kekerasan yang rendah pada weld metal bisa diakibatkan oleh terbentuknya porositas.

\section{DAFTAR PUSTAKA}

[1] Liang Y, Shen J, Hu S, Wang H, Pang J, Effect of TIG current on microstructural and mechanical properties of 6061-T6 aluminium alloy joints by TIG-CMT hybrid welding, Journal of Materials Processing Technology (2010),https://doi.org/10.1016/j.jmatprotec.201 7.12.006

[2] Kumar A \& Sundarrajan S. Effect of welding parameters on mechanical properties and optimization of pulsed TIG welding of Al-MgSi alloy, Int J Adv Manuf Technol (2009) 42:118-125 DOI 10.1007/s00170-008-1572-8

[3] Rajesh Manti \& Dwivedi D. K. \& Agarwal A. Microstructure and hardness of $\mathrm{Al}-\mathrm{Mg}-\mathrm{Si}$ weldments produced by pulse GTA welding, Int J Adv Manuf Technol (2008) 36:263-269 DOI 10.1007/s00170-006-0849-z

[4] Olabode, M., Kah, P., Martikainen, J., 2013. Aluminium alloys welding processes: Challenges, joint types and process selection. Proc. Inst. Mech. Eng. B. J. Eng. Manuf. 227 (8), 1129-1137.

[5] Padmanaban G, Balasubramanian V. Optimization of pulsed current gas tungsten arc welding process parameters to attain maximum tensile strength in AZ31B magnesium alloy. Nonferrous Met. Soc. China 21(2011) 467-476

[6] Ozturk F., Sisman A., Toros S., Kilic S., Picu R.C. Influence of aging treatment on mechanical properties of 6061 aluminum alloy. Materials and Design 31 (2010) 972-975

[7] Senthil Kumar T., Balasubramanian V., Sanavullah M.Y. Influences of pulsed current tungsten inert gas welding parameters on the tensile properties of AA 6061 aluminium alloy. Materials and Design 28 (2007) 2080-2092

[8] Wu C S, Zheng W and Wu L. Modelling the transient behaviour of pulsed current tungsteninert-gas weldpools. Modelling Simul. Mater. Sci. Eng. 7 (1999) 15-23.

[9] Kirk Webb, Mark Kadlec, Brad Hemmert, Current control contributes to weld productivity, quality. The Tube \& Pipe Journal April/May 2010 